\title{
Genes responsible for vaginal extracellular matrix metabolism are modulated by women's reproductive cycle and menopause
}

Oksana Shynlova, Maria A. T. Bortolini, May Alarab

Samuel Lunenfeld Research Institute, Mount Sinai Hospital (OS, MATB, MA); Division of Urogynecology and Reconstructive Pelvic Surgery, Mount Sinai Hospital, University of Toronto (MATB, MA) and Department of Obstetrics \& Gynecology, University of Toronto (OS, MA), Toronto, Canada

\section{ABSTRACT}

Objectives: To analyze the expression of genes involved in extracellular matrix (ECM) biogenesis and remodeling in vaginal tissue of women with clinically normal pelvic floor support (defined as controls) according to the phase of menstrual cycle and postmenopausal women with and without pelvic organ prolapse (POP).

Materials and Methods: This study examined the expression of matrix metalloproteinases (MMPs), their tissue inhibitors (TIMPs), and the Lysyl oxidase (LOX) family genes in the anterior vaginal wall of Caucasian women by real-time RT-PCR. Initially, mRNA expression was assessed in premenopausal controls in the secretory (group $1, n=10$ ) vs. proliferative (group 2, $\mathrm{n}=8$ ) phase of menstrual cycle. In addition, we compared premenopausal controls in the proliferative phase (group 2) vs. postmenopausal controls (group 3, $n=5$ ). Finally, we analyzed postmenopausal controls (group 3) vs. postmenopausal women with advanced POP (group 4, $\mathrm{n}=13$ ).

Results: According to the phase of menstrual cycle, MMP1 was significantly reduced ( $p$ $=0.003$ ), whereas the expression of TIMP1 and LOXL4 was significantly up-regulated during proliferative phase (both $\mathrm{p}<0.01$ ) when compared to the secretory phase in premenopausal control women. Regarding menopausal status/ageing, all MMPs were down-regulated, while TIMP3, TIMP4 and LOXL2 were significantly up-regulated in postmenopausal control women when compared to premenopausal controls $(p=0.005, p=$ 0.01 and $p<0.001$, correspondingly). TIMP4 and LOXL2 mRNA levels were significantly decreased in postmenopausal POP patients compared to asymptomatic postmenopausal controls ( $\mathrm{p}<0.01$ for both).

Conclusions: Our results indicate that ovarian cycle and age-related changes influence the expression of genes encoding proteins responsible for ECM metabolism in human vagina. Moreover, POP is associated with alteration in vaginal ECM components after menopause.

\section{ARTICLE INFO}

\section{Key words:}

Tissue Inhibitor of

Metalloproteinases;

Menopause; Vagina;

Metabolism; Genes

Int Braz J Urol. 2013; 39: 257-67

Submitted for publication:

May 23, 2012

Accepted after revision:

January 10, 2013

\section{INTRODUCTION}

Pelvic organ prolapse (POP) results from the failure of the pelvic floor support (1). Similar to stress urinary incontinence, POP is a serious health problem for women of all ages (2). Currently,
POP affects almost half of all women older than 50 years and it is estimated that $11.1 \%$ of them will have prolapse or incontinence surgery by age of 80 (3).

Epidemiological studies have shown that race, parity, ageing and ovarian hormones depri- 
vation after menopause are some of the risk factors for POP $(4,5)$. Findings of estrogen receptors (ERs) in the structures that support the pelvic organs, including the vagina, corroborate for the ovarian hormones modulation of the pelvic floor $(6,7)$. Molecular studies provide addition support for the association between ovarian hormones and POP. Serum estradiol levels and ER are significantly lower $(\mathrm{p}<0.01)$ in the uterine ligaments of women who had POP than in controls without POP before menopause (8). Also, decreased levels of estrogen and progesterone receptors have been described in postmenopausal POP women compared to asymptomatic ones ( $p<0.0001)(9)$.

Collagens and elastin are the two major extracellular matrix (ECM) components of the pelvic floor connective tissues, providing resistance to stretching and other tensile forces, and elasticity and resilience to the tissues, respectively. Cross-linking of tropoelastin and procollagen to form mature functional collagen and elastin fibers is performed by one or more members of the Lysyl oxidase (LOX) family of enzymes (10). On the other hand, collagen is degraded by a family of Metalloproteinases (MMPs) which are regulated by theirs tissue inhibitors (TIMPs) (11). There is a general agreement that pelvic floor tissues of patients with POP present decrease in the total collagen content, with higher rate of immature collagen more susceptible to rupture as compared with women without prolapse (12), and that deficiency of ECM components underlies POP. However, studies that have examined connective tissue content of prolapsed vaginal wall, collagen/elastin metabolism and remodelling $(13,14)$ often produce discrepant data possibly due to the population heterogeneity regarding age, race and hormonal status.

In our previous studies enrolling a population controlled by hormonal status and ethnicity, we detected a significant reduction of LOX, LOX like 1 (LOXL1) and LOXL3 gene and protein levels in vaginal samples of Caucasian premenopausal patients with POP as compared to asymptomatic premenopausal women (15). In addition, the expression and the activity of MMPs were increased whereas the expression of all TIMPs was significantly decreased in samples of vaginal tissue taken from premenopausal women with POP compared to controls (16). It is plausible that deficient or defective ECM metabolism enzymes represent key factors responsible for the development of POP.

Hence, we hypothesize that physiological ovarian hormones variation modulates the expression of specific groups of enzymes responsible for the formation and degradation of collagen and/or elastin fibers in the human vagina. Based on our previous findings indicating that vaginal tissues from Caucasian premenopausal POP women show altered ECM metabolism $(15,16)$, and that menopause-related ovarian hormones deprivation influences the genesis of POP in women (17), we also believe that similar or different changes can be found in POP women after the menopause. Therefore, the three objectives of the present study were to identify the expression pattern of MMPs, TIMPs and LOXs family genes (Table-1) in the anterior vaginal tissue of Caucasian (1) premenopausal women without POP according to the menstrual cycle phase (proliferative vs secretory), (2) to investigate the effect of age-related menopause changes on their expression by comparing premenopausal vs. postmenopausal women without POP. (3) In addition we examined the expression of MMPs, TIMPs and LOXs in the vaginal biopsies of postmenopausal women with and without severe POP.

\section{MATERIALS AND METHODS}

\section{Patient's selection and Tissue Collection}

Institutional Review Board of Mount Sinai Hospital, University of Toronto approved this study. We recruited Caucasian women undergoing vaginal hysterectomy for cervical prolapse equal or greater than stage III by POP-Q (18) classification as "patients", and women with POP-Q of stage 0 undergoing total abdominal hysterectomy for benign conditions other than POP as "controls" (Surgical indication in Table-2). We rationalized that stage 0 is the "gold standard" for normal pelvic support. Women with history of urogenital malignancy, endometriosis, connective tissue disorders, emphysema, previous pelvic surgery, and on estrogen and/or progestogen or steroid therapy were excluded. The initial gynecological exam 
Table 1 - Simplified description of the main role of the studied ECM proteins.

\begin{tabular}{ll}
\hline Target Genes & \multicolumn{1}{c}{ Protein Functions } \\
\hline LOX & ECM Biogenesis: Maturation of collagen and elastin \\
LOXL1 & ECM Biogenesis: Maturation of collagen and elastin \\
LOXL2 & ECM Biogenesis: Maturation of collagen and elastin \\
LOXL3 & ECM Biogenesis: Maturation of collagen and elastin \\
LOXL4 & ECM Biogenesis: Maturation of collagen and elastin \\
MMP1 & ECM Remodelling: Degradation of collagen and elastin \\
MMP2 & ECM Remodelling: Degradation of collagen and elastin \\
MMP9 & ECM Remodelling: Degradation of collagen and elastin \\
MMP14 & ECM Remodelling: Degradation of collagen and elastin \\
TIMP1 & ECM Remodelling: Modulation of MMPs \\
TIMP2 & ECM Remodelling: Modulation of MMPs \\
TIMP3 & ECM Remodelling: Modulation of MMPs \\
TIMP4 & ECM Remodelling: Modulation of MMPs \\
\hline
\end{tabular}

was performed by the Urogynecology staff (MA), and by the Gynecology team at Mount Sinai Hospital during regular activities. One of the authors (MB or MA) obtained written informed consent, confirmed the POP staging of all participants, and collected clinical data a week before the surgical procedure. Demographic data included: age, bone mass index (BMI), parity, family history for POP (positive if mother or sister affected by $\mathrm{POP}$ ) and presence of SUI (diagnosed by physical exam with stress test and/or urodynamic evaluation). The patients were examined in the lying position with a referred full-bladder, and asked to perform the cought test and further Valsalva maneuver. The descensus of the vaginal compartments were measured at the maximum straining point using a $\mathrm{cm}$ scale ruler. Total vaginal length was measured at rest under POP reduction with a vaginal speculum. Afterward, straining examination in the standing position confirmed the full extent of the POP. The participants were divided in 4 groups according to the hormonal status and presence of POP. Group 1: premenopausal control women in the secretory phase of menstrual cycle $(\mathrm{n}=10)$; Group 2: premenopausal control women in the proliferative phase of menstrual cycle $(\mathrm{n}=$ 8); Group 3: postmenopausal control women (n = 5); Group 4: postmenopausal women with severe POP $(n=13)$. We considered women in the postmenopausal phase if they reported that their menstrual periods had stopped for more than a year, and as premenopausal if they were having regular periods over the preceding twelve months. The phase of menstrual cycle and the endometrial atrophy was confirmed by endometrial histology report of uterine specimens. After removal of the 
Table 2 - Patients` demographics.

\begin{tabular}{lcccc}
\hline Study groups & $\begin{array}{c}\text { Group 1 } \\
\text { Premenopausal secretory } \\
\text { controls }\end{array}$ & $\begin{array}{c}\text { Group 2 } \\
\text { Premenopausal } \\
\text { proliferative controls }\end{array}$ & $\begin{array}{c}\text { Group 3 } \\
\text { Postmenopausal } \\
\text { controls }\end{array}$ & $\begin{array}{c}\text { Group 4 } \\
\text { Postmenopausal POP } \\
\text { patients }\end{array}$ \\
\hline $\mathrm{n}$ & 10 & 8 & 5 & 13 \\
Mean Age & $46.2( \pm 3)$ & $43.2( \pm 4)$ & $57( \pm 8)^{\dagger}$ & $67.5( \pm 7.1)^{*}$ \\
Mean BMI & $31 \pm 6.2)$ & $26.8( \pm 6.5)$ & $27.6( \pm 8.3)$ & $26.21( \pm 5.7)$ \\
Mean Parity & $1.6(1.4)$ & $1.72(0.3)$ & $1.6(1.3)$ & $3.56(1.6)^{*}$ \\
SUI (\%) & 0 & 0 & 0 & $54 \%{ }^{*}$ \\
Family History of POP (\%) & 0 & $11 \%$ & 0 & $54 \%{ }^{*}$ \\
Stage of POP (n, \%) & Stage 0 (10) & Stage 0 (8) & Stage 0 (5) & III C (8, 61.5\% $)^{*}$ \\
Indication for Hysterectomy & Fibroids (8) & Fibroids (8) & Endometrial & POP (13) \\
& Adenomyosis (2) & & Hyperplasia (3) &
\end{tabular}

findicates statistical difference between Group 2 and 3 .

*indicates statistical difference between Group 3 and 4 .

uterus, full thickness tissue specimen (approximately $1 \mathrm{~cm}^{2}$ ) was obtained by sharp dissection down to the avascular space of loose areolar tissue of the vagina using Metzenbaum scissors. The dissected structure corresponds to the adventitia layer that separates the vaginal from the bladder muscularis (19). As easily torn during dissection, adventitia was excluded from our analysis. To account for variations in stretch conditions and muscularis thickness throughout the vaginal length (20), the site of tissue collection was standardized at the anterior middle portion of the vaginal vault for all study groups. The authors (MB or MA), not blinded for the samples status, immediately received the tissue biopsies from the surgeon in the operative room and further performed the biochemical assays under direct supervision of the senior author (OS). Vaginal biopsy samples were washed in ice-cold PBS, flash-frozen in liquid nitrogen and stored at $-80^{\circ} \mathrm{C}$ for RT-PCR analysis.

\section{Real Time-Polymerase Chain Reaction (PCR)} Analysis

Reverse transcription (RT): RNA was extracted from the frozen tissues using TRIZOL (Gibco, Burlington, ON), column purified using RNeasy Mini Kit (Qiagen, Mississauga, Canada) and treated with $2.5 \mu \mathrm{L}$ DNase I (2.73 Kunitz unit/ $\mu \mathrm{L}$, Qiagen). $2 \mu \mathrm{g}$ of RNA was reverse transcribed into cDNA in a total reaction volume of $100 \mu \mathrm{L}$ using the TaqMan Reverse Transcription Kit (Applied Biosystems, CA, USA). To assess for genomic DNA contamination in the RNA samples, a "RT (-) control" was used.

Real-time PCR protocol: The primer sequences were generated through Primer Express 2.1 (ABI), verified for specificity by BLAST analyses and designed to span from two adjacent exons ((15) Table-3). 20ng of cDNA from the previous step was subjected to Real-time PCR in a total reaction volume of $20 \mu \mathrm{L}$ containing SYBR Green Master Mix (BioRad) using Eppendorf realplex 
Table 3 - Real-time PCR primer sequences of a panel of genes studied and housekeeping genes.

\begin{tabular}{|c|c|c|}
\hline Target Genes & Primer Sequences & GenBank accession \# \\
\hline LOX & $\begin{array}{l}\text { Forward 5' - AGGCCACAAAGCAAGTTTCTG - 3' } \\
\text { Reverse 5' - AACAGCCAGGACTCAATCCCT - 3' }\end{array}$ & NM_002317 \\
\hline LOXL1 & $\begin{array}{l}\text { Forward 5' --CTGTGACTTCGGCAACCTCAA - 3' } \\
\text { Reverse 5' - TGCACGTCGGTTATGTCGAT - 3' }\end{array}$ & NM_005576 \\
\hline LOXL2 & $\begin{array}{l}\text { Forward 5' - TCGAGGTTGCAGAATCCGATT - 3' } \\
\text { Reverse 5' - TTCCGTCTCTTCGCTGAAGGA - 3' }\end{array}$ & NM_002318 \\
\hline LOXL3 & $\begin{array}{l}\text { Forward 5' - CGGATGTGAAGCCAGGAAACT- 3' } \\
\text { Reverse 5' - AGGCATCACCAATGTGGCA - 3' }\end{array}$ & NM_032603 \\
\hline LOXL4 & $\begin{array}{l}\text { Forward 5' - ACCGGCATGACATTGATTGC - 3' } \\
\text { Reverse 5' - CATCATACTTGCAGCGGCACT - 3' }\end{array}$ & NM_032211 \\
\hline MMP1 & $\begin{array}{l}\text { Forward 5' - TACGAATTTGCCGACAGAGATG- 3' } \\
\text { Reverse 5'-GCCAAAGGAGCTGTAGATGTCC- 3' }\end{array}$ & NM_002421 \\
\hline MMP2 & $\begin{array}{l}\text { Forward 5' - GAATACCATCGAGACCATGCG-3' } \\
\text { Reverse 5'-CGAGCAAAGGCATCATCCA- 3' }\end{array}$ & NM_004530 \\
\hline MMP9 & $\begin{array}{l}\text { Forward 5' - CCTCGAACTTTGACAGCGACA- 3' } \\
\text { Reverse 5'-AATGATCTAAGCCCAGCGCGT- 3' }\end{array}$ & NM_004994 \\
\hline MMP14 & $\begin{array}{l}\text { Forward 5' - TGCCATGCAGAAGTTTTACGG-3' } \\
\text { Reverse 5'- CCTTCGAACATTGGCCTTGAT- 3' }\end{array}$ & NM_004995 \\
\hline TIMP1 & $\begin{array}{l}\text { Forward 5' - TTCTGGCATCCTGTTGTTGCT- 3' } \\
\text { Reverse 5'-CCTGATGACGAGGTCGGAATT- 3' }\end{array}$ & NM_003254 \\
\hline TIMP2 & $\begin{array}{l}\text { Forward 5' - GCGTTTTGCAATGCAGATGTAG- 3' } \\
\text { Reverse 5'- TCTCAGGCCCTTTGAACATCTT- 3' }\end{array}$ & NM_003255 \\
\hline TIMP3 & $\begin{array}{l}\text { Forward 5' - CTGCTGACAGGTCGCGTCTA- 3' } \\
\text { Reverse 5'-GCTGGTCCCACCTCTCCAC- 3' }\end{array}$ & NM_000362 \\
\hline TIMP4 & $\begin{array}{l}\text { Forward 5' - TCTGAACTGTGGCTGCCAAAT } \\
\text { Reverse 5'-AGCTTTCGTTCCAACAGCCAG- 3' }\end{array}$ & NM_003256 \\
\hline АСТВ & $\begin{array}{l}\text { Forward 5'- ACCTTCAACACCCCAGCCATGTACG - 3' } \\
\text { Reverse 5' -CTGATCCACATCTGCTGGAAGGTGG - 3' }\end{array}$ & NM_001101 \\
\hline SDHA & $\begin{array}{l}\text { Forward 5' -TGGGAACAAGAGGGCATCTG- 3' } \\
\text { Reverse 5' - CCACCACTGCATCAAATTCATG - 3' }\end{array}$ & NM_004168 \\
\hline YWHAZ & $\begin{array}{l}\text { Forward 5'-ACTTTTGGTACATTGTGGCTTCAA - 3' } \\
\text { Reverse 5' -CCGCCAGGACAAACCAGTAT - } 3 \text { ' }\end{array}$ & NM_003406 \\
\hline TBP & $\begin{array}{l}\text { Forward 5' - TGCACAGGAGCCAAGAGTGAA - } 3 \\
\text { Reverse 5' - CACATCACAGCTCCCCACCA - 3' }\end{array}$ & NM_003194 \\
\hline
\end{tabular}


Mastercycler (Eppendorf, Hamburg, Germany). After PCR, a dissociation curve was constructed by increasing temperature from $65^{\circ} \mathrm{C}$ to $95^{\circ} \mathrm{C}$ to verify the specificity of PCR products. In addition, a no-template control $\left(\mathrm{H}_{2} \mathrm{O}\right.$ control) was analyzed for possible contamination in the master-mix. A cycle threshold (Ct) mean value was recorded for each sample. PCR reactions were set up in triplicates and the mean of the 3 Cts was calculated. Values obtained for each gene were normalized to the geometric mean of 3 housekeeping genes: TBP, SDHA, YWHAZ and/or ACTB (21). A comparative Ct method ( $\triangle \Delta C T$ method) (22) was applied to the raw $\mathrm{Ct}$ values to find a relative gene expression. mRNA levels for premenopausal proliferative phase women were expressed relative to secretory phase levels, mRNA levels for postmenopausal control patients were expressed as fold changes relative to the premenopausal control levels or to POP patients expression levels. Validation experiments were performed to ensure that the PCR efficiencies between the target genes and the housekeeping genes were approximately equal.

\section{Statistical analysis}

Unpaired comparison of the MMPs, TIMPs and LOX family gene expression in the study groups was performed using Wilcoxon rank-sum test (Prism version 4.02). Fisher's exact test was used to compare differences in the family history of POP and the incidence of SUI between the groups. The level of significance was set at $\mathrm{P}<0.05$. Results were reported as mean \pm SEM.

\section{RESULTS}

Demographic data of four study groups population are summarized in Table-2. The groups were matched for race and BMI, however postmenopausal controls (Group 3) were older than premenopausal controls (Group 2) (57 vs. 43.2 years, respectively); and postmenopausal POP patients (Group 4) were significantly older than the controls (Group 3) (67.5 vs. 57 years, respectively) ( $p<0.05$ for both). Mean parity, family history of POP and incidence of SUI were significantly higher in patients when compared to controls in postmenopausal phases (Groups
3 and 4) $(\mathrm{P}<0.05)$. In POP group, the majority of the women had stage III cervical prolapse.

To examine the effect of endocrine environment on ECM turnover in women with normal pelvic floor support, we first compared the expression of MMPs, TIMPs and LOXs (Table-1) between premenopausal groups (Groups 1 vs. 2, Figure-1). MMPs (MMP1, -2, -9, -12, -14), TIMPs (TIMP1, $-2,-3,-4)$ and LOX (LOX, LOXL1, -2,-3,-4) family transcripts were expressed in all tissue samples.

Figure 1 - ECM remodeling gene expression in vaginal tissue of premenopausal women. Real-time quantitative RT-PCR analyses were performed on total RNA to compare the level of expression of (A) MMPs, (B) TIMP1-4 and (C) LOX, LOXL1-4 in vaginal wall biopsy samples from premenopausal asymptomatic women in the proliferative phase (empty bars, $n=8$ ) and the secretory phase of the menstrual cycle (black bars, $n$ $=10$ ). . The results represent the mean \pm S.E.M. A significant difference is indicated by * $(p<0.05)$.

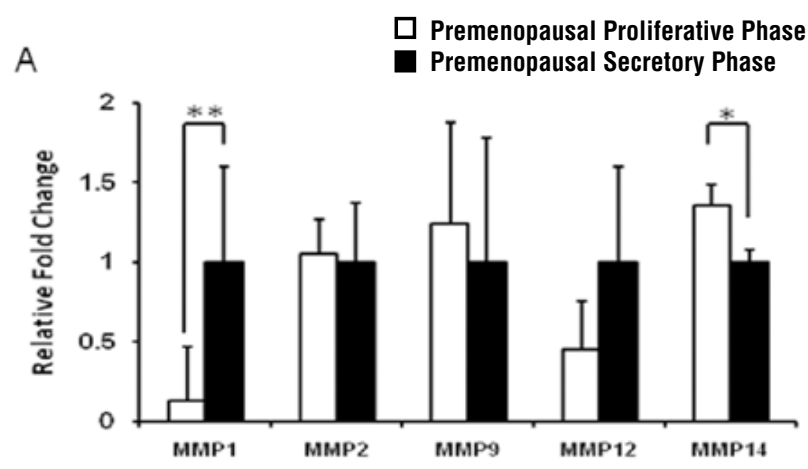

$\mathrm{B}$

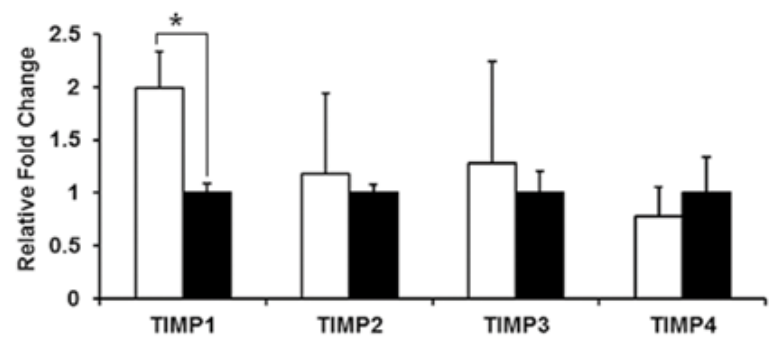

C

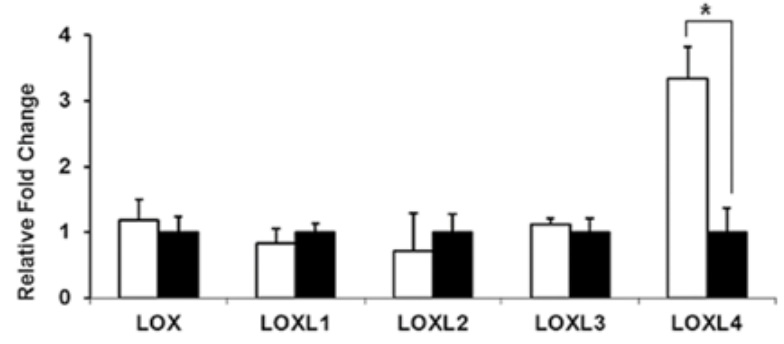


MMP1 transcript levels were significantly decreased ( $p<0.05)$, whereas MMP14 mRNA was significantly up-regulated $(\mathrm{p}=0.04)$ (Figure-1A), TIMP1 mRNA was significantly higher $(\mathrm{p}<0.01)$ (Figure-1B), and LOXL4 mRNA levels were significantly increased $(\mathrm{p}<0.01)$ (Figure-1C) in vaginal samples collected from control women in the proliferative phase of their menstrual cycle as compared to the secretory phase.

We also examined the expression of the same genes in control premenopausal women compared to control postmenopausal women to explore the influence of advancing age and physiological ovarian hormones deprivation (Groups 2 vs. 3, Figure-2). The expression levels of all genes were reduced after menopause; moreover MMP1 and MMP12 mRNA were undetectable (Figure-2A). TIMP3 and TIMP4 were significantly elevated in the postmenopausal compared to the premenopausal women ( $\mathrm{p}=0.005$ and 0.01 , respectively) (Figure-2B). Interestingly, LOXL2 expression was 10 times higher in vaginal samples of postmenopausal compared to premenopausal control women (Groups 2 vs. 3) (Figure-2C).

Figure 2 - Expression of genes responsible for ECM metabolism in vaginal tissue of premenopausal and postmenopausal women. Real-time quantitative RT-PCR analysis of (A) MMP-2,-9,-14, (B) TIMP1-4 and (C) LOX, LOXL1-4 mRNA expression in vaginal samples from asymptomatic premenopausal (empty bars, $n=8$ ) and postmenopausal women (thatched bars $n=$ 5). The results represent the mean \pm SEM. A significant difference is indicated by * $(P<0.05)$.

A

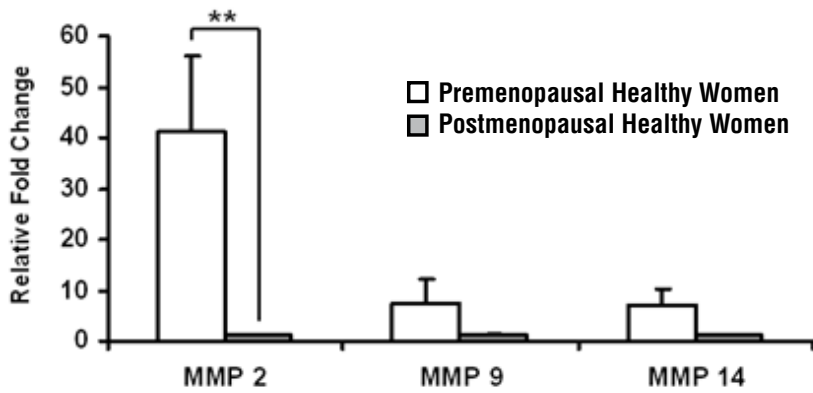

B
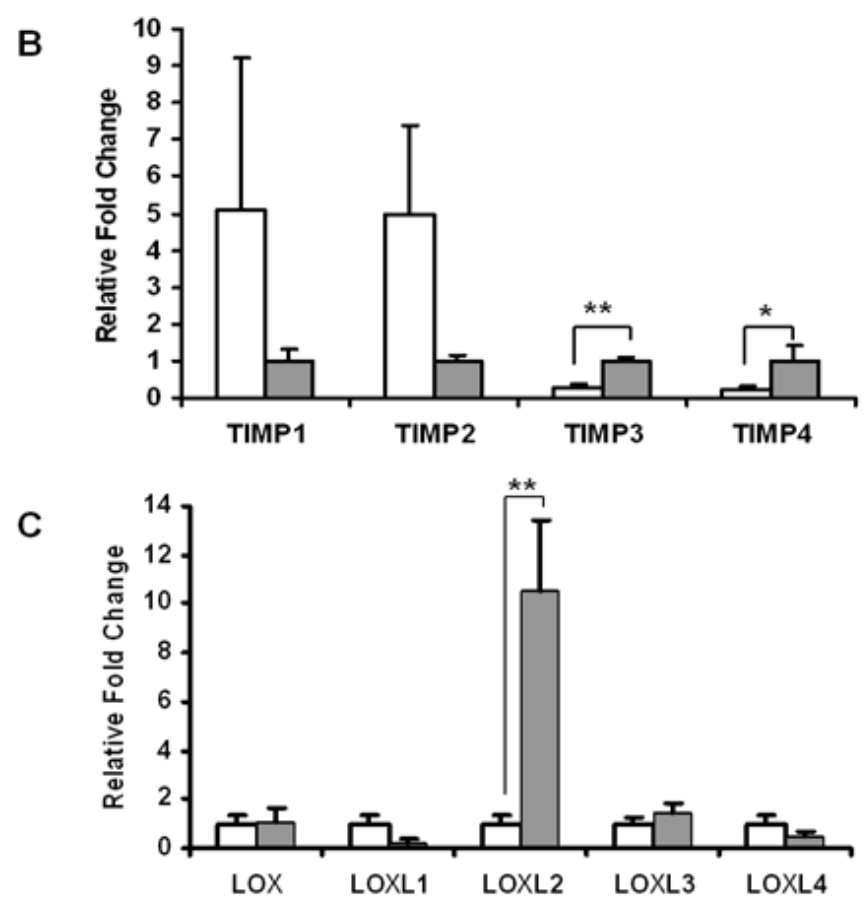
Our next goal was to compare the expression of MMPs, TIMPs and LOXs in postmenopausal POP patients versus postmenopausal asymptomatic controls (Group 3 vs. 4) (Figure-3). No MMPs expression was found in postmenopausal POP patients using the experimental conditions described in the Methods part of the manuscript. The quality of mRNA was confirmed by three different housekeeping genes. We also noticed that mRNA levels for all members of TIMP family were reduced in postmenopausal POP patients as compared to the asymptomatic postmenopausal controls, however only significantly for TIMP4 gene $(p=0.002)$ (Figure-3A). LOXL2 mRNA level was significantly reduced in postmenopausal patients with prolapse compared to postmenopausal control patients $(\mathrm{p}=$ 0.004). No significant difference between the two groups was observed for other LOX family genes (Groups 3 vs. 4) (Figure-3B).

\section{DISCUSSION}

POP is a disorder of multifactorial etiology $(4,5)$. In our research, we tried to overcome some of the epidemiological biases often observed in POP studies by including a strictly homogeneous set of Caucasian women with particular hormonal status confirmed histologically.

Few data have shown that overall collagen metabolism is activated in the proliferative phase, while elastin metabolism changes are more pronounced in the secretory phase of the menstrual cycle $(23,24)$. It is well described that reproductive organs are influenced by ovarian hormones during the menstrual cycle, pregnancy and menopause. The reproductive tract underwent cyclic remodelling in women's life span, with constant turnover of elastic and collagen fibres $(25,26)$. In this study we have shown differential

Figure 3 - Analysis of TIMPs and LOX family gene expression in vaginal tissue of postmenopausal patients with severe POP and postmenopausal asymptomatic controls. Real-time quantitative RT-PCR analysis of (A) TIMP1-4 and (B) LOX, LOXL1-4 mRNA expression in vaginal samples from asymptomatic control patients (thatched bars, $n=5$ ) and POP patients (vertical striped bars, $n=13)$. The results represent the mean $\pm S E M$. A significant difference is indicated by * $(P<0.05)$.
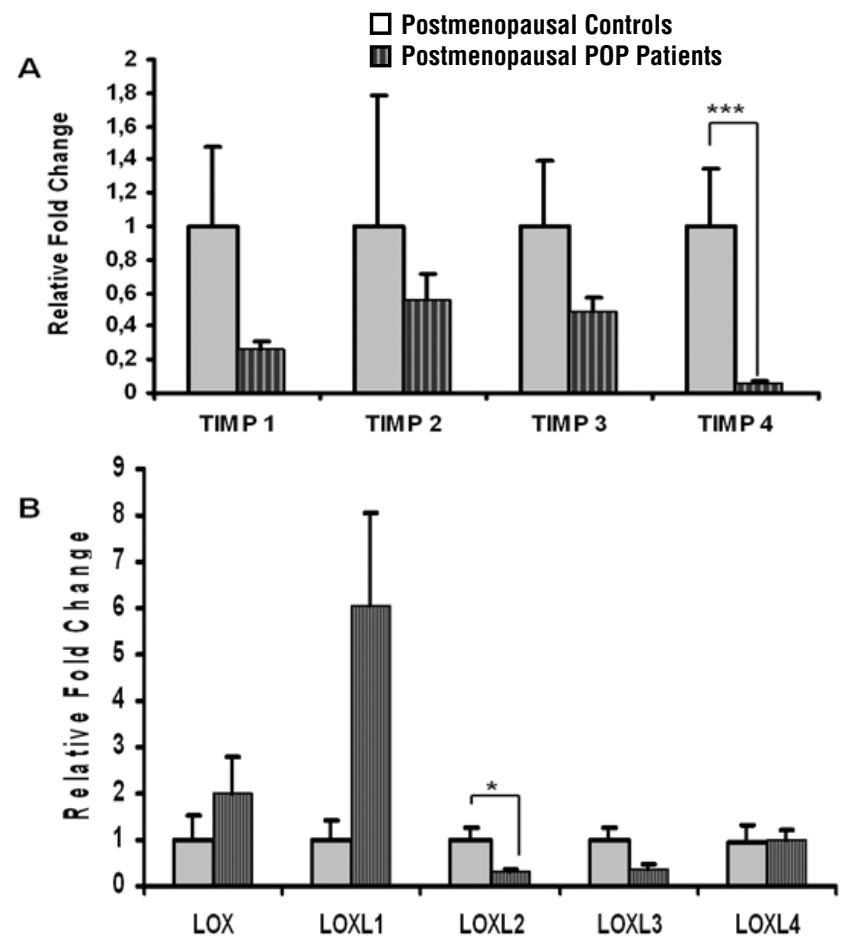
expression of ECM remodelling genes MMP1 and TIPM1 from vaginal tissue samples of asymptomatic premenopausal women in the proliferative (estrogen dominated) phase compared to the secretory (estrogen/progestogen regulated) phase of the menstrual cycle. As TIMPs proteins are the major physiological inhibitors of MMPs, our data suggest that estrogen and progestogen may control vaginal collagen metabolism, and the estrogen environment is protective against collagen degradation via MMP1/TIMP1 homeostasis.

Our results are consistent with Chen and colleagues who showed an estrogen-mediated increase in TIMP1 expression in cultured fibroblasts from human vagina (27), as well as increased overall collagen metabolism during the proliferative phase of the menstrual cycle (18). Differently from MMP1 regulation, MMP14 gene expression was significantly increased in the proliferative versus the secretory phase of the menstrual cycle, suggesting that MMP14 expression might be regulated by estrogen. We also detected a significant increase in LOXL4 mRNA expression during the estrogen-dominant proliferative phase compared to the secretory phase. Although the information regarding hormonal modulation of human LOXL4 is scarce in the literature, in mouse vagina however the timing of LOXL4 elevation coincides with an increase in estrogen and a decrease of progesterone plasma concentration, supporting our results and pointing to the positive effect of estrogen on the expression of this gene (28). Taking together, we have concluded that genes responsible for vaginal ECM metabolism are modulated by the hormonal fluctuation during the menstrual cycle.

Ovarian hormones deficiency and ageing are also known to influence the quality of pelvic floor tissue. In accordance to our original hypothesis that physiological ovarian hormones variation can regulate ECM degrading proteins, we found that the expression of all MMPs studied was dramatically down-regulated in women after menopause. The transcripts for MMP1 and MMP12 were below the detection level of Real-time PCR instrument. It was also the reason we were not able to compare the expression of all proteinases in the postmenopausal POP group. As premenopausal women were significantly younger than postmenopausal women we speculated that advancing age has a major impact on the matrix-degrading enzymes. Surprisingly, we discovered that LOXL2 enzyme was significantly up-regulated in postmenopausal compared to premenopausal women without POP. Earlier report has confirmed an association of LOXL2 to Werner syndrome, which is characterized by premature aging (29), suggesting a potential connection between ageing and LOXL2 expression.

Positive family history of POP and the incidence of concomitant SUI were significantly higher in POP patients compared to controls, suggesting a possible familial inheritance of genes involved in the pathophysiology of this condition. Similar to what we previously found in premenopausal POP patients (16), we have shown that all TIMPs were decreased in vaginal biopsies of postmenopausal POP patients compared to controls indicating that the mechanism of their regulation is independent of menopausal status. Chen et al. detected a decrease of TIMP1, but not of TIMP2 and TIMP3 expression in vaginal tissue of pre- and postmenopausal patients with SUI and POP (14). Liang et al. however found the decrease in TIMP2 mRNA in uterosacral ligament but not in the cervical tissue of uterine prolapse women compared to controls (30). Our gene expression results reinforce other studies with regards to the reduction of TIMP1 in women with POP compared to asymptomatic controls (29).

We have previously described that the expression of LOX, LOXL1 and LOXL3 genes and proteins is diminished in premenopausal POP patients compared to asymptomatic controls (15). Here, we analyzed LOXs family genes and their possible association with POP in postmenopausal women. Our results showed that LOXL2 gene was significantly down-regulated in the vagina of postmenopausal patients with severe POP as compared to postmenopausal controls, corroborating with the idea that the ECM biogenesis is affected in women with POP. This finding suggests that advancing age and ovarian hormones deprivation modulate vaginal ECM components of women affected by POP as they were much older than postmenopausal women with normal floor sup- 
port. It is probable that the molecular mechanisms underlying POP in women after menopause are different from the ones observed in premenopausal women. Importantly LOX enzymes and their substrate elastin expression also diminish with age (31); this correlation may reflect an increased incidence of pelvic floor diseases in the elderly population. However, the cause/effect relationship between the interval from menopause onset and development of defects in the ECM components in older POP patients is not elucidated. Future studies are needed to clarify those issues.

However, our study has limitations. The difficulty of obtaining adequate tissue sample according to our strict selection criteria (especially for the postmenopausal control group) has restricted the number of participants enrolled. The size of the tissue specimen also limited us to use only one methodology in the study, namely gene expression but not the protein expression analysis, which complicates the understanding of the basic biologic conditions of POP. We also acknowledge that the postmenopausal study groups were not matched for parity, a known factor in POP development.

\section{CONCLUSIONS}

In this study we have confirmed that vaginal tissue of Caucasian women with normal pelvic floor support before and after menopause shows different levels of ECM turnover and stability under physiological hormonal variances. In addition, we have shown that age and menopause influence the expression of genes involved in the ECM biogenesis and remodeling in vaginal tissues of older women with POP. We speculate that molecular mechanisms involving vaginal ECM deficiency in POP differ between women before and after menopause. The alteration in the expression of genes coding for MMPs, TIMPs and LOXs enzymes suggests that their protein expression and activities in pre- and postmenopausal tissues should be targets for future investigations. A better understanding of complex molecular mechanisms underlying POP before and after menopause will expand the diagnostic and clinical treatment capability. We encourage researches to acknowledge the hormonal status of the study candidates in relation to pelvic floor connective tissue disorders.

\section{ACKNOWLEDGEMENT}

The authors gratefully thank Nadiya Oleksiv for her assistance in the RT-PCR analyses. We also thank Dr Stephen Lye and Dr Harold Drutz for stimulating discussions.

\section{SOURCE OF FUNDING}

University of Toronto, Faculty of Medicine Dean's Fund- New Staff Grant and Research Fund, Department of Obstetrics and Gynecology, Mount Sinai Hospital, Toronto.

\section{CONFLICT OF INTEREST}

None declared.

\section{REFERENCES}

1. DeLancey J0: Anatomy and biomechanics of genital prolapse. Clin Obstet Gynecol. 1993; 36: 897-909.

2. Subak LL, Waetjen LE, van den Eeden S, Thom DH, Vittinghoff $E$, Brown JS: Cost of pelvic organ prolapse surgery in the United States. Obstet Gynecol. 2001; 98: 646-51.

3. Olsen AL, Smith VJ, Bergstrom JO, Colling JC, Clark AL: Epidemiology of surgically managed pelvic organ prolapse and urinary incontinence. Obstet Gynecol. 1997; 89: 501-6.

4. Bump RC, Norton PA: Epidemiology and natural history of pelvic floor dysfunction. Obstet Gynecol Clin North Am. 1998; 25: 723-46.

5. Moalli PA, Jones Ivy S, Meyn LA, Zyczynski HM: Risk factors associated with pelvic floor disorders in women undergoing surgical repair. Obstet Gynecol. 2003; 101: 869-74.

6. Copas P, Bukovsky A, Asbury B, Elder RF, Caudle MR: Estrogen, progesterone, and androgen receptor expression in levator ani muscle and fascia. J Womens Health Gend Based Med. 2001; 10: 785-95.

7. Skala CE, Petry IB, Albrich SB, Puhl A, Naumann G, Koelbl $\mathrm{H}$ : The effect of hormonal status on the expression of estrogen and progesterone receptor in vaginal wall and periurethral tissue in urogynecological patients. Eur $\mathrm{J}$ Obstet Gynecol Reprod Biol. 2010; 153: 99-103. 
8. Lang JH, Zhu L, Sun ZJ, Chen J: Estrogen levels and estrogen receptors in patients with stress urinary incontinence and pelvic organ prolapse. Int J Gynaecol Obstet. 2003; 80: $35-9$.

9. Bai SW, Chung DJ, Yoon JM, Shin JS, Kim SK, Park KH: Roles of estrogen receptor, progesterone receptor, p53 and p21 in pathogenesis of pelvic organ prolapse. Int Urogynecol J Pelvic Floor Dysfunct. 2005; 16: 492-6.

10. Kagan HM, Li W: Lysyl oxidase: properties, specificity, and biological roles inside and outside of the cell. J Cell Biochem. 2003; 88: 660-72.

11. Shapiro SD: Matrix metalloproteinase degradation of extracellular matrix: biological consequences. Curr Opin Cell Biol. 1998; 10: 602-8.

12. Jackson SR, Avery NC, Tarlton JF, Eckford SD, Abrams P, Bailey AJ: Changes in metabolism of collagen in genitourinary prolapse. Lancet. 1996; 347: 1658-61.

13. Moalli PA, Shand SH, Zyczynski HM, Gordy SC, Meyn LA: Remodeling of vaginal connective tissue in patients with prolapse. Obstet Gynecol. 2005; 106: 953-63.

14. Chen BH, Wen Y, Li H, Polan ML: Collagen metabolism and turnover in women with stress urinary incontinence and pelvic prolapse. Int Urogynecol J Pelvic Floor Dysfunct. 2002; 13: 80-7; discussion 87.

15. Alarab M, Bortolini MA, Drutz H, Lye S, Shynlova O: LOX family enzymes expression in vaginal tissue of premenopausal women with severe pelvic organ prolapse. Int Urogynecol J. 2010; 21: 1397-404.

16. Alarab M, Shynlova 0, Drutz H, Lye S: Extracellular Matrix remodeling is increased in Vaginal Tissue of Premenopausal Patients with Pelvic organ Prolapse. Reproductive Sci. 2008; 15 (Suppl 1): abstract \#311A

17. Tinelli A, Malvasi A, Rahimi S, Negro R, Vergara D, Martignago $\mathrm{R}$, et al.: Age-related pelvic floor modifications and prolapse risk factors in postmenopausal women. Menopause. 2010; 17: 204-12.

18. Bump RC, Mattiasson A, Bø K, Brubaker LP, DeLancey JO, Klarskov $P$, et al.: The standardization of terminology of female pelvic organ prolapse and pelvic floor dysfunction. Am J Obstet Gynecol. 1996; 175: 10-7.

19. Ricci JV, Lisa JR, et al.: The relationship of the vagina to adjacent organs in reconstructive surgery; a histologic study. Am J Surg. 1947; 74: 387-410.

20. Boreham MK, Wai CY, Miller RT, Schaffer JI, Word RA: Morphometric analysis of smooth muscle in the anterior vaginal wall of women with pelvic organ prolapse. Am J Obstet Gynecol. 2002; 187: 56-63.

21. Meller M, Vadachkoria S, Luthy DA, Williams MA: Evaluation of housekeeping genes in placental comparative expression studies. Placenta. 2005; 26: 601-7.
22. Schmittgen TD, Livak KJ: Analyzing real-time PCR data by the comparative C(T) method. Nat Protoc. 2008; 3: 1101-8.

23. Chen B, Wen Y, Zhang Z, Guo Y, Warrington JA, Polan M: Microarray analysis of differentially expressed genes in vaginal tissues from women with stress urinary incontinence compared with asymptomatic women. Hum Reprod. 2006; 21: 22-9.

24. Chen B, Wen Y, Zhang Z, Wang H, Warrington JA, Polan ML: Menstrual phase-dependent gene expression differences in periurethral vaginal tissue from women with stress incontinence. Am J Obstet Gynecol. 2003; 189: 89-97.

25. Woessner JF, Brewer TH: Formation and breakdown of collagen and elastin in the human uterus during pregnancy and post-partum involution. Biochem J. 1963; 89: 75-82.

26. Vassilev V, Pretto CM, Cornet PB, Delvaux D, Eeckhout $Y$, Courtoy PJ, et al.: Response of matrix metalloproteinases and tissue inhibitors of metalloproteinases messenger ribonucleic acids to ovarian steroids in human endometrial explants mimics their gene- and phase-specific differential control in vivo. $J$ Clin Endocrinol Metab. 2005; 90: 5848-57.

27. Chen B, Wen $\mathrm{Y}$, Wang H, Polan ML: Differences in estrogen modulation of tissue inhibitor of matrix metalloproteinase- 1 and matrix metalloproteinase-1 expression in cultured fibroblasts from continent and incontinent women. Am J Obstet Gynecol. 2003; 189: 59-65.

28. Mogami H, Keller P, Acevedo JF, Word RA: Differential regulation of Lysyl oxidases in uterine and cervical tissues during pregnancy, parturition, and the puerperium. Reproductive Sciences. 2010; 17(Suppl 3): 76A, abstract \# 34.

29. Murano S, Thweatt R, Shmookler Reis RJ, Jones RA, Moerman EJ, Goldstein S: Diverse gene sequences are overexpressed in werner syndrome fibroblasts undergoing premature replicative senescence. Mol Cell Biol. 1991; 11: 3905-14.

30. Chen BH, Wen Y, Li H, Polan ML: Collagen metabolism and turnover in women with stress urinary incontinence and pelvic prolapse. Int Urogynecol J Pelvic Floor Dysfunct. 2002; 13: 80-7; discussion 87.

31. Pascual G, Mendieta C, Mecham RP, Sommer P, Bellón JM, Buján J: Down-regulation of lysyl oxydase-like in aging and venous insufficiency. Histol Histopathol. 2008; 23: 179-86.

Correspondence address:

Dr. Oksana Shynlova, Samuel Lunenfeld Research Institute at Mount Sinai Hospital, 25 Orde st, Suite 6-1019

Toronto, Ontario, Canada. M5G1X5 Fax: 416-586-5993

E-mail: shynlova@lunenfeld.ca 